University of Nebraska - Lincoln DigitalCommons@University of Nebraska - Lincoln

US Army Research

U.S. Department of Defense

2012

\title{
Differentiating transformational and non- transformational leaders on the basis of neurological imaging
}

Pierre A. Balthazard

Arizona State University, pierreb@asu.edu

David A. Waldman

Arizona State University

Robert W. Thatcher

Applied Neuroscience Research Institute

Sean T. Hannah

West Point - United States Military Academy

Follow this and additional works at: http://digitalcommons.unl.edu/usarmyresearch

Balthazard, Pierre A.; Waldman, David A.; Thatcher, Robert W.; and Hannah, Sean T., "Differentiating transformational and nontransformational leaders on the basis of neurological imaging" (2012). US Army Research. 265.

http://digitalcommons.unl.edu/usarmyresearch/265

This Article is brought to you for free and open access by the U.S. Department of Defense at DigitalCommons@University of Nebraska - Lincoln. It has been accepted for inclusion in US Army Research by an authorized administrator of DigitalCommons@University of Nebraska - Lincoln. 


\title{
Differentiating transformational and non-transformational leaders on the basis of neurological imaging
}

\author{
Pierre A. Balthazard ${ }^{\mathrm{a}, *}$, David A. Waldman ${ }^{\mathrm{a}}$, Robert W. Thatcher ${ }^{\mathrm{b}}$, Sean T. Hannah ${ }^{\mathrm{c}}$ \\ ${ }^{a}$ W. P. Carey School of Business, Arizona State University, USA \\ ${ }^{\mathrm{b}}$ EEG and Neurolmaging Laboratory, Applied Neuroscience Research Institute, USA \\ ${ }^{c}$ Center for the Army Profession and Ethic, West Point - United States Military Academy, USA
}

\section{A R T I C L E I N F O}

Available online 22 September 2011

\section{Keywords:}

Transformational leadership

Social cognitive neuroscience

Discriminant analysis

\begin{abstract}
A B S T R A C T
The purpose of this study was to evaluate the viability of using neurological imaging to classify transformational leaders, versus non-transformational leaders, as identified through existing psychometric methods. Specifically, power spectral analysis measures based on electroencephalograms (EEG) were used to develop and validate a discriminant function that can classify individuals according to their transformational leadership behavior. Resting, eyes closed EEG was recorded from 19 scalp locations for 200 civilian and military leaders. We also assessed follower or peer perceptions of transformational leadership through the use of the Multifactor Leadership Questionnaire (MLQ). Our discriminant analysis, which involved a two-step, neural variable reduction and selection process, was $92.5 \%$ accurate in its classification of leaders. Patterns in the spectral measures of the brain of leaders, including activity and network dynamic metrics, are discussed as potential correlates of transformational leadership behavior. The current work provides a better understanding of the latent and dynamic neurological mechanisms that may underpin the transformational leadership qualities of individuals.
\end{abstract}

(c) 2011 Elsevier Inc. All rights reserved.

The transformational leadership paradigm has been predominant in the literature over the past 25 years and has been the focus of numerous studies examining leadership and its effects (Judge \& Piccolo, 2004; Lowe, Kroeck, \& Sivasubramaniam, 1996). This paradigm emphasizes how exceptionally effective leaders interact with followers in a manner that inspires them to higher levels of performance and commitment to their organizations. Transformational leaders do so through the articulation of strongly-held beliefs and values and visionary communication (Bass \& Bass, 2009). In addition, they are likely to show individualized consideration with regard to the developmental needs of followers, and they encourage innovative thinking and problem-solving through intellectual stimulation (Bass \& Avolio, 1994). In general, research has consistently shown positive effects of transformational leadership with regard to individual, group, and organizational performance (Judge \& Piccolo, 2004; Lowe et al., 1996).

Given the relevance of such leadership to effectiveness in organizations, some researchers have turned their attention to its etiology and whether personal characteristics can be identified that predict its formation (e.g., Judge \& Bono, 2000). In other words, there is an increased recognition of the need to understand how transformational leadership, and its perception on the part of followers, may be traced to personal qualities of the leader. For example, Judge and Bono (2000) and Bono and Judge (2004) attempted to show possible linkages between Big Five personality factors and the display of transformational leadership. Because their findings suggested only modest relationships, Bono and Judge (2004, p. 907) concluded that future research should move beyond looking at the relationship between transformational leadership and the Big Five factors, and instead, look at "narrower traits" or take alternative approaches.

Accordingly, the current research takes such an alternative approach, although perhaps beyond the realm of possibilities that Bono and Judge (2004) had originally envisioned. Specifically, using power spectral analysis of electroencephalograms (also

\footnotetext{
* Corresponding author.

E-mail address: pierreb@asu.edu (P.A. Balthazard).
} 
referred to as quantitative EEG or qEEG methodology), we examine the neurological correlates of transformational leadership. We chose to apply EEG, which uses computer-based, advanced signal, processing techniques to produce data about the brain through the placement of electrodes along the scalp and skull (Niedermeyer \& Silva, 1995). Specifically, researchers can now measure precisely the electrical and magnetic energy in the brain. Based on such measurement, precise calculations can be ascertained with regard to location and types of electrically-based variables (Scherg, 1990). Although an assessment of the pros and cons of various neuroimaging techniques is beyond the scope of our paper, we should note that in comparison to other methods, EEG has excellent temporal resolution, is relatively inexpensive, and its use involves no health risk. Furthermore, as a result of EEG assessment of leaders, the data produced from spectral analysis can be readily used for the types of statistical analyses, including the discriminant analysis described below, with which leadership and social science researchers are familiar.

Discriminant analysis allows researchers to study the differences between two or more groups of entities with respect to multiple variables simultaneously (Huberty, 1994). This technique has been employed to address a variety of research issues, such as salesman selection (Perreault, French, \& Harris, 1977), economic, demographic, and attitudinal characteristics of credit-card holders (Awh \& Waters, 1974), voting behavior (DeCotiis \& LeLouarn, 1981), and school principal leadership styles (Fridell, Newcom-Belcher, \& Messner, 2009). The method has also been used in the neuroscience literature to, for instance, relate EEG variables to intelligence (Thatcher, North, \& Biver, 2005), to mild head trauma (Thatcher, Walker, Gerson, \& Geisler, 1989), and the effects of drug use on brain morphology (Sowell et al., 2010). The current approach involves an attempt to identify a discriminant function that could delineate relatively more transformational versus relatively less transformational leaders.

We see such research as fitting within a broader set of emerging approaches to understanding leadership that involve biologically-based factors. For example, Arvey and colleagues have done extensive work using twins to show a genetic basis for leadership role occupancy (Arvey, Rotundo, Johnson, Zhang, \& McGue, 2006; Arvey, Zhang, Avolio, \& Krueger, 2007; Zhang, Ilies, \& Arvey, 2009). The current research can add to an understanding of biological correlates of leadership. In particular, we see our research as being in line with the emerging, interdisciplinary field of social cognitive neuroscience that seeks to understand human interactions at the intersection of social, cognitive, and neural spheres of science (Ochsner \& Lieberman, 2001). More specifically, organizational cognitive neuroscience could be viewed as an applied form of social cognitive neuroscience that seeks to analyze and understand human behavior within organizational settings (Butler \& Senior, 2007). Senior, Lee, and Butler (2011, p. 806) proposed that neuroscience approaches to organizational issues such as leadership allow researchers to "examine problems within a wider analytic framework, which in turn allows for the development and testing of additional hypotheses."

There are several advantages to the neurologically-based, research approach used in the current study. First, psychometric assessments of leadership represent the dominant mode of measuring leadership qualities. Yet, they are inherently fraught with problematic issues, such as information processing influences, rating errors, and so forth, that can affect their validity (Lord \& Maher, 1991). Ultimately, leadership assessment based at least partially upon neurological variables may provide a more ecologically-sound addition to the arsenal of tools used to assess leadership. Second, neurological variables may help provide a better understanding of why leaders behave in the manner in which they are observed. That is, if areas of the brain, as well as neurological variables emanating from those areas, can be associated with effective (or poor) leader behavior, then insights may be gained with regard to that behavior. These possibilities, as well as our research approach and findings, are described in more detail below.

\section{Is there a neurological pattern associated with transformational leadership?}

Based on emerging evidence, we propose that the answer to this question may be yes. Further, because of the emerging technology outlined above, the pursuit of this question is now feasible in very operational terms. Specifically, neuroscience literature would suggest that an understanding of the connection between neurological activity and transformational leadership will need to recognize that leader behaviors are complex and will not map neatly into a single discrete location in the brain (Cacioppo et al., 2003). For example, Lieberman (2007) noted that different networks of brain regions are activated and linked for social-cognitive tasks that focus attention on our interactions with others. Accordingly, such complex phenomena as vision formation or other aspects of transformational leadership behavior are likely to require multiple parts of the brain acting jointly in terms of a distributed, but yet interconnected, set or network of neuronal regions (Cacioppo, Berntson, \& Nusbaum, 2008; Nolte, 2002). Fortunately, there is a growing cognitive neuroscience literature that examines human behaviors in relation to brain complexity-generally understood as the study of the network organization in the brain (Bosl et al., 2011; Buzaski, 2006). Although transformational leadership has not to our knowledge been examined using a neurophysiological lens, it nevertheless shares commonalities with other behaviors that have been shown to be associated with brain functioning.

There are two general principles of brain complexity that emerge as relevant in the study of transformational leadership. First, there are likely to be significant roles for the frontal and temporal lobes as predictors of effective leadership behaviors. For instance, the frontal cortex is understood to be especially responsible for executive functioning such as self-regulation, which involves processes that program, control, and verify sensory information processing in the planning and organizing of behaviors (Lewis, 1997). It is considered as the top of a hierarchy of neural structures that integrate external information and internal states for the representation, temporal organization, and execution of complex mental and behavioral responses to environmental challenges, such as those involved in transformational leadership (Case, 1992; Fuster, 1999). Indeed, leaders' ability to monitor and regulate their thoughts and behavior through executive control functions has been proposed as a critical enabler of leader flexibility (Zaccaro, Foti, \& Kenny, 1991). 
In contrast, the temporal lobes have been shown to play a critical role in memory, perception, language, and personality (Damasio, 1989). The hippocampal system, located in this region, is important for forming a coherent set of memories of people and events and for recalling them in understanding engagements in the present (Cohen, Kaplan, Moser, Zuffante, \& Jenkins, 1999), thus providing effective leaders with the acumen needed when faced with leadership challenges (Hannah, Woolfolk, \& Lord, 2009). The temporal lobes also mediate the balance between one's psychobiological state and transactions with others and the environment (Craig, 2009; Schore, 1994). That is, as transformational leadership requires highly adept, social perception (e.g., for individualized consideration) and reasoning skills (e.g., for intellectual stimulation), the temporal lobes are central to those functions, and thus activity in these regions may be germane.

Second, related to patterns of integration and differentiation in the activity among various neuronal units across the brain, there is the potential for hemispheric differences in brain activity and brain connectivity. Indeed, hemispheric asymmetries would suggest that the left and right cerebral hemispheres of the brain may differ to some extent in their information processing abilities and tendencies or biases (Hellige, 1990). For example, Hellige (1990) offered some evidence that suggests that the left hemisphere is largely responsible for the rational or analytic consideration of details when making decisions. As such, increased levels of differentiation within that hemisphere would indicate improved ability to discriminate between details, alternatives, or courses of action, and thus, more complexity of thinking.

Conversely, increased levels of integration, or "holistic processing" (Hellige, 1990, p. 59) within the right hemisphere, could suggest a contribution to emotional balance through integration in the processes that manage emotional thought (Craig, 2009; Jones, Field, \& Davalos, 2000). Emotional control of oneself and the understanding of emotional reactions on the part of others may also be relevant to transformational leadership, for example, in the display of individualized consideration or the development of a vision that will appeal to the emotions or affect of followers. Along these lines, it has been shown that dysfunction in the right frontal portion of the brain results in an inability to understand relationships with other people, i.e., social skills, mood control, and awareness of self (Salloway, Malloy, \& Duffy, 2001) or difficulties balancing emotions in decision-making under conditions of uncertainty (Naqvi, Shiv, \& Bechara, 2006).

The right hemisphere of the brain might also be key to understanding how leaders form a greater understanding of the bigger picture when reasoning and making decisions (Thatcher, North, \& Biver, 2008). For example, the right frontal portion of the brain has been associated with big picture thinking, foresight, and insight-all of which may be relevant to the formulation of vision (Aziz-Zadeh, Kaplan, \& Iacoboni, 2009; Carrillo-de-la-Pena \& Garcia-Larrea, 2007), which is a key element of transformational leadership (Bass \& Bass, 2009; Lowe et al., 1996).

It should be noted that some research is now beginning to emerge that specifically attempts to connect neurological activity to leader behavior. For example, using EEG technology, Waldman, Balthazard, and Peterson (2011) recently reported that socialized (rather than personalized) visionary communication is related to EEG coherence in the right frontal regions of the brain. As described in more detail below, the assessment of EEG coherence provides estimates of the strength of connectivity between various regions of the brain (Nunez, 1981; Thatcher, Krause, \& Hrybyk, 1986).

\subsection{An inductive approach}

The above review helps to set the stage for considering the theoretical bases on which to proceed with examinations of the neurological foundations of transformational leadership. Indeed, as summarized above, prior neurologically-based research has identified brain activity that may underpin the abilities and orientations that have been theorized to promote transformational leadership. Nevertheless, despite the efforts described thus far, leadership research in conjunction with neuroscience inherently adds a new and complex dimension to theory development; that is, phenomena and variables associated with neurological activity in various regions of the brain. To illustrate the complexity of theory development in this domain, consider how transformational leader behavior itself is multifaceted in terms of its basis and manifestation. That is, effective leader behavior is likely to reflect a combination of emotional balance or control on the part of the leader, emotional understanding by the leader of his/her of followers, foresight or insight, communication skills, and so forth. Moreover, these elements of leader behavior may be based on somewhat disparate types of brain activity or variables that emanate from multiple regions of the brain. However, the point here is that any a priori, theoretical connection between brain activity and transformational leadership would first need to decompose specific behaviors of concern. Then, theory and evidence would need to be gleaned from existing neuroscience literature to gain clues regarding potentially relevant neurological activity to the decomposed parts. Hypotheses could then be potentially formed linking neurological activity to specific leader behavior.

Butler and Senior (2007, p. 5) characterized this process in terms of "both theory forming and theory honing because it will help to winnow theories about which cognitive processes facilitate various social behaviors." Lee and Chamberlain (2007, p. 22) referred to "layers of theory that one could overlay on the basic neural activity of the brain." With these issues in mind, it is clear that despite the rapid accumulation of findings in neuroscience literatures, as well as recent findings pertaining specifically to visionary communication (Waldman et al., 2011), theory and research attempting to connect neuroscience and leadership are still at a nascent stage of development. As such, an argument could be made that effort should be directed toward the inductive building of theory through a broad analysis of neurological variables.

Along such lines, examples exist in the neuroscience literature in which discriminant analyses have been used inductively to simply detect or isolate neurological differences between individuals with high versus low amounts of a particular quality, such as attention deficit disorder (ADD) or other clinical issues (Thatcher, Biver, \& North, 2003; Thatcher, Walker, Biver, North, \& Curtin, 2003). Although problematic forms of behavior (e.g., ADD) have largely been the subject of prior research along these lines, it is 
possible to put more of a focus on positive forms of behavior, such as transformational leadership. Research of this nature could be used to more inductively form theory about the nature of neurological activity that may be especially relevant to such forms of effective leader behavior.

\subsection{Research questions}

Congruent with the above line of thinking, we pursued an inductive approach in the current study. The overall goal was to evaluate the ability of power spectral analysis of EEG to discriminate between participants receiving relatively high transformational leadership scores (obtained through survey measures), versus those receiving relatively low scores. If successful, then neurological patterns derived from qEEG data could then be used to inform us as to the most promising neurological variables that might distinguish transformational leadership qualities in individuals. That is, based on EEG data, we attempted to define a discriminant function that could accurately delineate high versus low transformational leadership. To the best of our knowledge, this research represents the first attempt to operationalize a neuroscientific approach in conjunction with a psychometric assessment of transformational leadership. In sum, we ask the following research questions:

Research question \#1: Can a discriminant function of power spectral analysis variables be defined to classify, with accuracy, those leaders exhibiting transformational leadership behaviors from those who do not?

Research question \#2: Are there particular features (e.g., types of qEEG variables, location of those variables, and so forth) of the power spectral analysis that are more discriminative of transformational leadership than others?

Research question \#3: Based on qEEG data, are there anatomical or topographic patterns in the human brain that are indicative of transformational leadership?

\section{Method}

\subsection{Participants}

Our sample consisted of 200 individuals, including 135 business and/or community leaders from a variety of industries (including education, law, hospitality, engineering, healthcare, banking and finance, consulting, nonprofits, retail, and publishing), 33 mid-career U.S. Army officers (e.g., Majors, Captains), and 32 officers-in-training at a military academy in the U.S. Criteria that would lead to exclusion from the study included previous head trauma, neurological or neurovascular disease, or recent significant drug or alcohol use (within the prior 14 days). Demographic data revealed a sample that was approximately $44 \%$ female, with a mean age of 42 years, ranging from 21 (a military cadet) to the mid 70s (senior executives). The sample was relatively diverse ethnically, with approximately $58 \%$ being White/Caucasian. The modal level of education for the civilian sub-sample was "Master's degree," but included a range from "some college" (1 participant) to "Doctoral degree" (5 participants). To illustrate the senior level of these civilians, the modal salary reported was "\$125,001 plus," and $80 \%$ self-reported themselves as senior executives, professional, owner, or self-employed/entrepreneur. The median number of these senior leaders' direct and indirect reports was 25-99 individuals, although $20 \%$ of this sub-sample led organizations with significantly larger total workforces. The military subsample included 32 college students ( 7 with prior combat experience), 25 pursuing a specialized Master's degree, 4 holding a Master's degree, and 4 holding a doctorate degree. All post-graduate military participants had significant combat experience.

Beyond basic demographic information, data for leaders included over 800 transformational leadership assessments of the participants from "other" individuals. Participants and these other individuals were told that all of these assessments were strictly for research purposes and would remain confidential with the researchers. Participants were instructed to invite 3-5 other individuals who could provide a broad range of perspectives or information (especially with regard to leadership behavior), to respond to a web-based instrument. A minimum of three assessments from others was the number that we deemed necessary to achieve an accurate assessment. On average, approximately 4 assessments of transformational leadership for each of the respective participants were collected from others. Overwhelmingly, these other individuals (or respondents) were either current subordinates or peers, although a small number reported being in other roles such as professional colleagues. Ninety-six percent of them reported knowing their respective leader for 1 year or more. They also reported frequent interactions; $95 \%$ reported interacting with their leader more than several times a month.

\subsection{Power spectral analyses and measures}

In a face-to-face session, we fastened a set of 19 electrodes to the scalp of participants and collected typical neurological measures using an EEG device. EEG activity can be assessed in different frequency bandwidths, including: delta ( $1 \mathrm{to} 4 \mathrm{~Hz}$ ), theta ( $4 \mathrm{Ho} 8 \mathrm{~Hz}$ ), alpha ( 8 to $12 \mathrm{~Hz}$ ), beta (12 to $30 \mathrm{~Hz}$ ), and gamma (30 to $100 \mathrm{~Hz}$ ). An EEG segment of at least 3 min was recorded at a digitization rate of $128 \mathrm{~Hz}$ during an eyes-closed resting (but alert) condition for all participants. Each EEG record was visually examined and then edited to remove artifact supported by the Neuroguide® software program (from Applied Neuroscience, Inc.), which maintains artifacts rejection routines for eye movements, drowsiness, and instances where EEG voltage in any channel exceeds patterns that are typical of the participant's EEG. The program also controls for handedness and hemispheric dominance. A resulting minimum of $60 \mathrm{~s}$ of artifact-free EEG was obtained for 
each participant. Split-half reliability tests and test re-test reliability tests were conducted on the edited EEG segments, and only records with $>95 \%$ reliability were kept for subsequent spectral analysis.

Spectral analysis is one of the standard methods used for quantification and statistical analyses of the EEG, and is the basis for modern quantitative EEG (or qEEG). In general, two categories of qEEG variables are studied as potential correlates of human behavior: (1) power or amplitude measures and derivatives, and (2) network connection measures. First, the power measures reflect the 'frequency content' of the signal or the distribution of signal power over frequency across all locations in the brain. Several parameters derived from the power spectrum are examined in this study, including absolute and relative power for each frequency band, power ratios between frequency bands, peak frequency, and burst metrics. Second, network complexity measures in our study include amplitude asymmetry, coherence, phase shift amplitude, and phase shift/lock duration.

In our effort to define a relationship between neurological functioning and transformational leadership, we examined 16 classes of qEEG variables as identified in Table 1 . These spectral analyses produced 10,393 unique data points for each participant analyzed. Short explanations for the spectral measures used in our study appear below.

It is important to note that the neural data collected in our study represent the brain's intrinsic activity (i.e., activity not directly related to a task or event). A growing community of neuroscience researchers suggests that the neural operations when the brain is in a baseline or at rest state (i.e., participant is in an alert but relaxed state with eyes closed) can most accurately reflect the brain functioning and capacity of an individual (Raichle \& Snyder, 2007). Cacioppo et al. (2003) noted that the brain in such a resting state is not passive, but rather involves its own set of potentially meaningful mental operations. Indeed, Kjaer, Nowak, and Lou (2002) showed that neural activity associated with the self was similar while at rest, as compared to completing a self-awareness task. Interestingly, there are many brain regions that actually show decreases in activity upon task activation (Raichle \& Gusnard, 2002; Shulman et al., 1997).

\subsubsection{Power and amplitude measures}

Interestingly, the source of $50 \%$ of the electricity captured by the EEG apparatus is generated directly beneath the recording electrode, and approximately 95\% within a $6 \mathrm{~cm}$ radius of the electrode location on the scalp (Nunez, 1981, 1995). The energy characteristics emanating from the 19 channels in our study have been correlated with such measures as capacity to learn (Marosi et al., 1999) and intelligence (Jausovec \& Jausovec, 2001; Schmid, Tirsch, \& Scherb, 2002). As such, it would seem important to include channel-specific power and amplitude measures in any qEEG investigation of transformational leadership.

For each of the different frequency bands, absolute and relative power measures were thus computed from the 19 scalp locations. Absolute power quantifies the activity at each frequency band for that channel (e.g., electrode). Relative power is the percentage of each bandwidth relative to the total power in each channel. From these basic values, amplitude and power ratios are derived. EEG amplitude is computed as the square root of power. Power ratios are additional measures that provide greater detail in the assessment of relative power combinations in each channel.

Locally-connected neurons recruit neighboring neurons with a sequential build up of electrical potential that is referred to as the EEG 'burst activity' and 'spindles' (Steriade, 1995; Thatcher \& John, 1977). A burst represents a significant departure from the baseline level of the instantaneous power of the EEG in any particular frequency band. As such, several 'burst' measures were also calculated, including burst amplitude, burst duration, and number of bursts per second. Concomitantly, the inter-burst interval is

Table 1

The number and categories of qEEG variables.

\begin{tabular}{|c|c|c|c|}
\hline qEEG measures & Observations & Total & Retained \\
\hline \multicolumn{4}{|l|}{ Power (Activity level) ${ }^{\mathrm{a}}$} \\
\hline Absolute Power (AP) & 11 frequency groups at 19 channels & 209 & $6^{c}$ \\
\hline Relative Power (RP) & 11 frequency groups at 19 channels & 209 & 1 \\
\hline Peak Frequency (PK) & 11 frequency groups at 19 channels & 209 & 1 \\
\hline Power Ratios (PR) & 10 ratio sets at 19 channels & 190 & 3 \\
\hline Burst Amplitude Mean (BM) & 9 frequency groups at 19 channels & 171 & 4 \\
\hline Burst Amplitude SD (BAD) & 9 frequency groups at 19 channels & 171 & 3 \\
\hline Burst Duration Mean (BDM) & 9 frequency groups at 19 channels & 171 & 0 \\
\hline Burst Duration SD (BDD) & 9 frequency groups at 19 channels & 171 & 3 \\
\hline Burst per Second (BPS) & 9 frequency groups at 19 channels & 171 & 1 \\
\hline Inter-burst Interval Mean (IBM) & 9 frequency groups at 19 channels & 171 & 2 \\
\hline Inter-burst Interval SD (IBD) & 9 frequency groups at 19 channels & 171 & 2 \\
\hline \multicolumn{4}{|l|}{ Network Complexity ${ }^{\mathrm{b}}$} \\
\hline Amplitude Asymmetry (AA) & 11 frequency groups at 171 variables & 1881 & 11 \\
\hline Coherence $(\mathrm{COH})$ & 11 frequency groups at 171 variables & 1881 & 11 \\
\hline Phase Shift-Amplitude Mean (PAM) & 9 frequency groups at 171 variables & 1539 & 0 \\
\hline Phase Shift-Duration Mean (PD) & 9 frequency groups at 171 variables & 1539 & 5 \\
\hline \multirow[t]{2}{*}{ Phase Shift-Lock Duration (PL) } & 9 frequency groups at 171 variables & 1539 & 5 \\
\hline & & 10,393 & 58 \\
\hline
\end{tabular}

Notes:

a These measures are derived from the activity recorded by each of the 19 electrodes in the International 10/20 system.

b These measures are derived from the comparison of activity between the 171 electrode combinations in the International $10 / 20$ system (e.g., 19 electrodes $\times 18$ neighboring electrodes $=171$ combinations $)$.

c Number of variables that were selected from a two-step variable reduction process and eneterd into a discriminant analysis of transformational leadership. 
the time between the falling phase of one burst and the rising phase of the subsequent burst. Bursts per second are computed by adding up the total number of bursts, and then dividing by the total amount of time in the selected record. The amplitude of a burst is the length (amplitude) at the maximum peak value of the burst. In sum, burst measures are an alternate mechanism to examine neuronal behavior. That is, when a group of neurons burst, they exhibit phase locking. When there is a large and sustained burst, this reflects a period of hyper-synchrony or high coherence (see below) for that region in the brain. Thus, shorter burst duration and lower number of bursts, indicate lower coherence and more differentiation.

\subsubsection{Brain network complexity measures}

Local groups of neurons are connected to distant groups of neurons $(3 \mathrm{~cm}$ to $21 \mathrm{~cm})$ via cortico-cortical connections (Braitenberg, 1978; Schultz \& Braitenberg, 2002), and may also be connected to more localized clusters or populations of neurons that exhibit significant phase differences or delays. Complexity in the brain is often defined by models of information theory and stochastic processes involving a balance between differentiation and integration (Buzaski, 2006; Tononi, Sporns, \& Edelman, 1994). Brain connectivity as measured by EEG coherence and phase relationships reflects a balance between local neural integration and long distance differentiation (Thatcher et al., 2008; Tononi et al., 1994).

A key neuroscience measure used to interpret the brain's network complexity is known as "coherence." The assessment of EEG coherence provides estimates of the strength of connectedness between various regions of the brain (Nunez, 1981; Thatcher et al., 1986). Because coherence is equivalent to the percent of variance accounted for, it is often simply presented in the form of a percentage. For example, $90 \%$ coherence would indicate relatively high coupling or integration between brain locations, while $10 \%$ coherence would indicate relatively low coupling or differentiation between the locations. A sampling of EEG coherence studies includes, for example, examinations of cognition (Babiloni et al., 2010; Kislova \& Rusalova, 2009; Martin-Loeches, Munoz-Ruata, Martinez-Lebrusant, \& Gomez-Jari, 2001), heritability (van Baal, Boomsma, \& de Geus, 2001; Van Beijsterveldt, Molenaar, de Geus, \& Boomsma, 1998), gender differences (Hanlon, Thatcher, \& Cline, 1999; Koles, Lind, \& Flor-Henry, 2010), intelligence (Anokhin, Lutzenberger, \& Birbaumer, 1999; Jausovec \& Jausovec, 2003), and various clinical disorders (Babiloni et al., 2010; De Vico Fallani et al., 2010).

The importance of EEG coherence in a study of leaders is that it can reveal aspects of the network dynamics in their brains. For example, as discussed above, coherence can estimate the number and the strength of connections between groups of neurons in different brain locations. EEG coherence has also been used in brain maturation studies to estimate the growth of network connections and changes in the complexity of networks (Gasser, Jennen-Steinmetz, \& Verleger, 1987; Hanlon et al., 1999; Thatcher et al., 2008). This is important because as noted earlier, most complex behavioral concepts, such as transformational leadership behavior, do not map into a single, discrete location in the brain (Cacioppo et al., 2003). Moreover, rather than only relying on the identification of isolated brain areas that might be associated with specific behaviors, Senior et al. (2011) suggested an examination of regions that may be operating together. Accordingly, we calculated separate coherence values for each of the 171 electrode combinations and for each frequency band.

An understanding of network complexity by using a measure of integration and differentiation (i.e., coherence) can be further enhanced by examining the related mechanisms of synchronization and desynchronization in the brain - a neuroscience concept known as phase reset. For example, measures of EEG phase reset have been used to analyze various frequency bands during cognitive tasks (Kahana, 2006; Tesche \& Karhu, 2000), working memory (Damasio, 1989; Rizzuto et al., 2003), brain development (Thatcher et al., 2008) and consciousness (John, 2002, 2005). In the present study, we used the two fundamental components of phase reset: (1) phase shift duration, and (2) phase lock duration. Phase reset occurs in coupled neuronal regions when there is a sudden shift of the phase relationship to a new value followed by a period of phase locking or phase stability between the regions (Pikovsky, Rosenblum, \& Kurth, 2003). Notably, well-managed periods of phase stability (lock) following a phase shift have been shown to lead to efficient brain activity (Cooper, Winter, Crow, \& Walter, 1965; Lopes Da Silva, 1995; Nunez, 1995).

Lastly, EEG amplitude asymmetry differences were computed as a ratio of differences in absolute power between two scalp locations or $(A-B / A+B) * 200$, whereby $A$ and $B$ are the absolute power recorded from two different electrode locations. When $A=B$, then amplitude asymmetry $=0$ (Thatcher, McAlaster, Lester, Horst, \& Cantor, 1983). This represents yet another measure of network complexity in the brain. The total number of qEEG variables available to the study, as well as the number of variables in different categories of the analyses, is shown in Table 1.

\subsection{Psychometric assessment of transformational leadership}

Transformational leadership assessments were obtained via internet-based surveys from the individuals described above within days or a few weeks following the EEG assessment of participants. In line with prior work, perceptions were assessed using the scales from the short form of the Multifactor Leadership Questionnaire (MLQ) (Bass \& Avolio, 1990), including four items for each of the following sub-scales: inspirational motivation $(\alpha=.89)$, idealized influence $(\alpha=.86)$, intellectual stimulation ( $\alpha=.81$ ), individualized consideration $(\alpha=.76)$, and attributed charisma $(\alpha=.77)$. Items were answered on a five-point scale ranging from (1) not at all to (5) to a very great extent. We should note that the MLQ typically involves 0-4 scaling with the highend anchor of "frequently, if not always." Our use of a 1-5 scale with a high anchor of "to a very great extent" yielded a mean score comparable to prior research involving the MLQ if prior research had recorded 1-5 scaling (Lowe et al., 1996). As is commonly the case in prior research (cf., Judge \& Piccolo, 2004; Lowe et al., 1996), we summed the scores of the 20 items that composed the above sub-scales to form an overall measure of transformational leadership for each study participant $(\alpha=.93)$. 
The appropriateness of aggregating individual-level transformational leadership responses to the group level was assessed by one-way analyses of variance (i.e., ANOVAs with focal leader as the independent variable and their leadership assessments from others as the dependent variable), as well as tests based on the multiple-item estimator $r_{w g(j)}$ (James, Demaree, \& Wolf, 1984, 1993). "The demonstration of consensus among individual perceivers within focal units provides the justification for aggregation that is, it substantiates the construct validity of higher level measurement" (Kozlowski \& Hattrup, 1992, p. 162).

The $\eta^{2}$ statistics for the dependent variables indicated that the target of the assessment explained $44 \%$ of the variance for the transformational leadership assessment. Similarly, the $F$ ratio $(F=2.61, \mathrm{p}<.001)$ suggested that the variance in responses by others for the different participants is significantly greater than the variance in responses by others targeting a specific participant. These values indicate that group membership explained a substantial and significant part of the variance in the responses with adequate reliability within the groups. Further, the median $r_{w g(j)}$ estimate for transformational leadership was .84, with a vast majority of assessment groups having values of $r_{w g(j)}$ equal to or above the .70 threshold, considered to represent satisfactory agreement (George, 1990; James et al., 1984). In order to not inflate agreement estimates, we calculated the $r_{w g(j)}$ estimates, adjusting for a small skew in the expected variance, following the guidelines given by James et al. (1984). The small-skew distribution appears to be a reasonably good approximation of obtained responses to leadership and attitude measures, similar to those employed in the present study (Shamir, Zakay, Breinin, \& Popper, 1998). In sum, the patterns of the ANOVA, variance explained, and $r_{w g(j)}$, suggested that it was appropriate to use the aggregate transformational leadership scores derived from the individual assessments of peers and followers for each participant in the study.

\subsection{Selection of variables for discriminant analysis}

The 200 participants were randomly separated into 2 sub-samples for the purpose of establishing: (1) a 100-participant 'test' group to define the discriminant function, and (2) a 100-participant 'validation' group to validate the function. To insure equivalency between the two sub-samples, equal numbers of each participant type (e.g., younger civilian, older civilian, junior military, senior military) were randomly assigned to each sub-sample. Indeed, there were no statistical differences in the demographic, neurological, or leadership characteristics of the sub-samples. For the purpose of establishing a discriminant function, the participants were further separated into a high transformational leadership (TFL) group (operationalized as one standard deviation above the mean value for the sample), versus a low TFL group (operationalized as one standard deviation below the mean). This approach represents a conservative mechanism to segregate participants into two clearly distinct groupings on the basis of their transformational leadership. In a first step with the test group, t-tests were conducted on all 10,393 qEEG measures defined in Table 1, and variables that were statistically related at the $\mathrm{p}<.05$ level to transformational leadership were identified. In a second step, the significant qEEG variables were then entered into a principal components analysis with varimax rotation to further reduce the measure sets. Following a process described in Thatcher et al. (2005), separate analyses were performed on each of the $16 \mathrm{qEEG}$ variable categories within the spectral analysis, and the highest loading variable for each factor was then identified for entry into the discriminant analysis. In concert with Thatcher et al. (2005), it is important to note that no correction for multiple comparisons was used (nor necessary) because the goal of this step was data reduction to separate the most significant variables from the less significant variables, rather than drawing an inferential conclusion.

Finally, the linear discriminant analysis was computed using IBM SPSS (2011). Sensitivity, specificity, positive predicted values (PPV) and negative predicted values (NPV) were defined as: sensitivity $=$ true positives $(\mathrm{TP}) /(\mathrm{TP}+\mathrm{false}$ negatives $(\mathrm{FN}))$. Specificity was defined as: true negatives $(\mathrm{TN}) /(\mathrm{TN}+$ false positives $(\mathrm{FP}))$. PPV $=(\mathrm{TP}) /(\mathrm{TP}+\mathrm{FP})$ and $\mathrm{NPV}=(\mathrm{TN}) /(\mathrm{FN}+\mathrm{TN})$.

\subsection{Validation by multiple regression analyses}

Multiple regression analysis (IBM SPSS, 2011) was conducted to independently validate the discriminant analysis (i.e., to compare to the discriminant analysis). The dependent variable was the predicted transformational leadership scores, and the independent variables were the set of qEEG variables that were entered into the discriminant analysis as described earlier. Two scatter plots were then generated to show related correlations. The first related the discriminant scores and the predicted transformational leadership scores for all participants. The second then related the predicted and measured transformational leadership scores for all participants. Such procedures are in line with the work of Thatcher et al. (2001, 2005) and others (e.g., Fridell et al., 2009; Perreault et al., 1977).

\section{Results}

The variable elimination process involved only the test sub-group $(\mathrm{N}=100)$ and resulted in the selection of 58 variables for the transformational leadership (TFL) discriminant analysis. Their distribution is shown in the right-hand column of Table 1 . The distribution shows that the process resulted in a 99.4\% reduction in the total variable space (e.g. 58/10,393) with a participant to variable ratio of 1.8. The greatest number of variables selected for the discriminant analyses were network complexity variables, in order: EEG coherence and amplitude asymmetry (19\% each), and phase shift/lock duration (8.6\% each), accounting for 55\% of the variables. Channel specific variables, in order, included: absolute power (10.3\%), then various burst measures, which accounted for the remaining $45 \%$ of those selected.

Table 2 shows a listing of the qEEG variables that were selected for the discriminant analysis. The letters F, T, C, P, and O stand for Frontal, Temporal, Central, Parietal, and Occipital locations, respectively, of the brain. Even numbers (i.e., 2, 4, 6, and 8) refer to 
Table 2

Final list of qEEG variables selected for the TFL discriminant analyses.

\begin{tabular}{|c|c|c|c|}
\hline Absolute power (6) & Burst duration SD (3) & \multicolumn{2}{|c|}{ Coherence (11) } \\
\hline Theta-F8 & Delta-F4 & Delta & Beta 1 \\
\hline Alpha $1-C z$ & High Beta-01 & Fp1F4 & C3T6 \\
\hline Beta $2-\mathrm{C} 4$ & High Beta-Fp1 & Theta & Beta 3 \\
\hline Beta 3-Fp1 & & 01T6 & P3T4 \\
\hline Gamma 1-F7 & Inter-burst Interval Mean (2) & $\mathrm{P} 402$ & High Gamma \\
\hline \multirow[t]{2}{*}{ Gamma 1-T3 } & Theta-Fp2 & Alpha 1 & F8T6 \\
\hline & Beta 2-01 & P4O2 & Gamma 2 \\
\hline Relative Power (1) & & Alpha 2 & F8T3 \\
\hline \multirow[t]{2}{*}{ High Beta-C4 } & Inter-burst Interval SD (2) & Fp1F7 & F8T4 \\
\hline & Beta 1-F3 & F4T4 & \\
\hline Phase Shift Duration (5) & Beta $3-\mathrm{Fz}^{\mathrm{a}}$ & & \\
\hline Theta & & Amplitude Asymmetry (11) & \\
\hline Fp1F7* & Burst per Second (1) & Theta & Beta 1 \\
\hline Alpha 1 & High Beta-Fz & F4T3 & $\mathrm{P} 402$ \\
\hline $\mathrm{C} 4 \mathrm{O} 2$ & & F7T6 & Beta 2 \\
\hline C4F8 & Burst Amplitude Mean (4) & Alpha 1 & F4P3* \\
\hline Alpha 2 & Alpha $1-C z$ & $\mathrm{FzCz}$ & High Beta \\
\hline $\mathrm{O} 2 \mathrm{Pz}$ & High Beta-F7 & F8T3 & C4F7 \\
\hline \multirow[t]{2}{*}{ P3Pz ${ }^{\mathrm{a}}$} & Beta $2-\mathrm{P} 4$ & Alpha 2 & High Gamma \\
\hline & Gamma-T3 & $\mathrm{F} 4 \mathrm{Fz}$ & $P 3 C z$ \\
\hline Phase Lock Duration (5) & & T3T4 & $\mathrm{P} 3 \mathrm{Pz}$ \\
\hline Delta & Burst Amplitude SD (3) & & \\
\hline F7F8 & Alpha $1-C z$ & Power Ratios (3) & \\
\hline Alpha 1 & Beta $1-C 4$ & Alpha/Beta-Fp1 & \\
\hline F4T5 & High Beta-F7 & Alpha/Beta-Pz & \\
\hline P401 & & Beta/High Beta-C4 & \\
\hline \multicolumn{4}{|l|}{ Beta 1} \\
\hline $\mathrm{F} 3 \mathrm{Fz}$ & & Peak Frequency (1) & \\
\hline Gamma & & High Beta-T3 & \\
\hline $\mathrm{C} 301$ & & & \\
\hline
\end{tabular}

\footnotetext{
a Denotes coefficient of the canonical discriminant function.
}

the right hemisphere, and odd numbers (i.e., 1, 3, 5, and 7) refer to the left hemisphere. The smaller the number, the closer the position of the electrode site to the midline or axis of the skull. The ' $z$ ' refers to an electrode placed on the midline. "Fp" stands for Frontal pole, or pre-frontal area of the brain. Table 2 also identifies the 4 variables that were ultimately retained as part of the standardized, canonical discriminant function. They were identified within the stepwise process that defines, at each step, the one variable among remaining variables that minimizes the overall Wilks' Lambda (thus explaining the most variance).

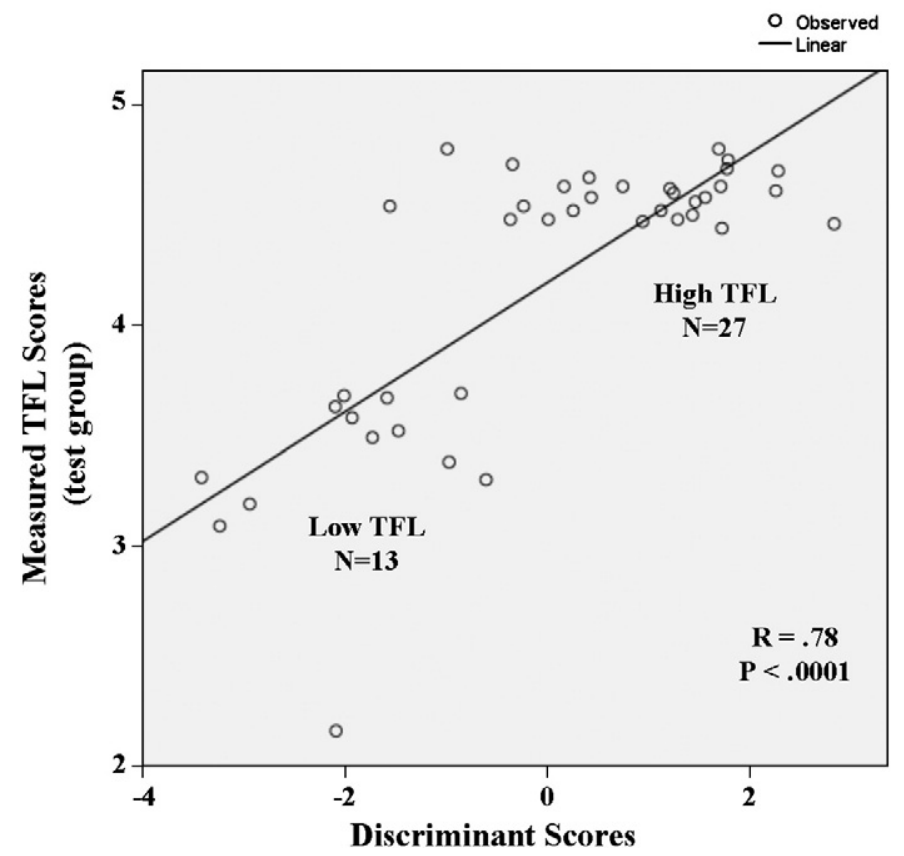

Fig. 1. Distribution of discriminant scores on the x-axis and transformational leadership scores on the y-axis, for low and high TFL participants in the 'test' group. 
Variables from the frontal and temporal lobe regions represent $65 \%$ of the retained variables. In addition, suggesting that lateralization theories (i.e., theories stressing the relevance of a particular hemisphere of the brain) must be considered with caution (Hellige, 1990; Hines, 1987), our analysis of transformational leadership showed remarkable balance in the number of qEEG variables emanating from each hemisphere.

Fig. 1 shows the results of the transformational leadership discriminant analysis derived from the test sub-sample, where the $\mathrm{x}$ - and $\mathrm{y}$-axes correspond to the discriminant and psychometrically measured TFL scores, respectively. Table 3 shows the results of the discriminant analysis of high TFL versus low TFL groups. With regard to Research Question \#1, overall classification accuracy was $92.5 \%$, sensitivity was $92.6 \%$, and specificity was $92.3 \%$. These represent relatively high discriminant performance values. The function also performed well on the validation sub-sample $(\mathrm{N}=100)$ with an overall accuracy of $86.7 \%$, sensitivity of $96.2 \%$, and specificity of $73.6 \%$.

\subsection{Cross-validation of intermediate TFL participants}

The qEEG discriminant function is a linear regression equation that returns a single value for each participant based on the qEEG variables and a unique set of regression coefficients (Norusis, 1994). The function, determined by the variables associated with the test sub-group $(N=100)$, generates coefficients for all participants $(N=200)$. As such, the discriminant function is not just a classifier of the probability of membership of a group; it may also serve as a linear estimate of values intermediate to the extreme values contained in the original high and low TFL groups that were discriminated (Thatcher et al., 2001). A simple yet accurate test of the linearity of a discriminant function is to determine if the discriminant scores for participants within the intermediate range of measured TFL scores (i.e. within one standard deviation of the mean TFL score) are indeed intermediate to the discriminant scores for the two extreme sub-groups of participants (i.e., high and low TFL sub-groups). We conducted a oneway ANOVA of the discriminant estimates by the three groupings (e.g., high, low, and intermediate TFL or "unselected") for the overall sample and found a statistically significant difference between the groups $(F=15.94, p<.001)$. It revealed estimate means and standard deviations of -1.91 (.87) for low TFL, and 0.92 (1.05) for high TFL participants. The mean and standard deviation of the intermediate or unselected group was 0.12 (1.74). Contrasting the intermediate or unselected group mean to the mean value for the full data set, 0.07 (1.70), the test indicates that indeed, the discriminant function is generally a linear predictor of transformational leadership. Fig. 2 shows the distribution of discriminant scores for the two extreme TFL groups, as well as the intermediate or unselected TFL participants. As can be seen, the discriminant function does behave as a linear estimator of TFL because the intermediate or unselected TFL participants produced intermediate discriminant scores.

\subsection{Cross-validation using multivariate regression analyses}

The finding that intermediate value TFL participants produce intermediate value discriminant scores indicates that multivariate regression analysis should yield results that are similar to the discriminant analysis. The advantage of crossvalidation using multivariate regression analyses is that there is no dependence upon discrimination between two groups of participants, such as low and high TFL groups, and a continuum of TFL predictions is possible. Thus, correlational analyses were conducted between the discriminant scores using the discriminant analysis and predicted TFL scores using the multivariate regression analysis. Fig. 3 shows the results of the correlation between the discriminant scores and predicted TFL scores using multivariate regression analysis in the total population $(\mathrm{N}=200)$. Fig. 3 reveals that there are statistically significant correlations between the multiple regression prediction of TFL and the discriminant scores from all participants in this study. Finally, as an additional test of the potential of qEEG predictions of TFL, we used a multiple regression analysis to evaluate the linearity and predictive accuracy of the EEG variables that were used in the discriminant analysis. In these analyses, the TFL scores were the dependent variables (y-axis), and the EEG measures were the independent variables ( $\mathrm{x}$-axis). Fig. 4 shows the plot of the relationship between the predicted TFL scores and the measured TFL scores. The multiple regression value $(R=.63)$ is statistically significant and indicative of linearity and good predictive accuracy of our discriminant function.

Table 3

Results of the discriminant analysis.

\begin{tabular}{|c|c|c|c|c|}
\hline & \multirow[t]{2}{*}{ TFL groups } & \multicolumn{3}{|c|}{ Classification results } \\
\hline & & $N$ & High TFL & Low TFL \\
\hline \multirow[t]{3}{*}{ Test sub-sample ${ }^{a}$} & High TFL & 27 & 25 (92.6\%) & $2(7.4 \%)$ \\
\hline & Low TFL & 13 & $1(7.7 \%)$ & $12(92.3 \%)$ \\
\hline & Ungrouped cases & 60 & $45(75 \%)$ & $15(25 \%)$ \\
\hline \multirow[t]{4}{*}{ Replication sub-sample } & High TFL & 26 & 25 (96.2\%) & $1(3.8 \%)$ \\
\hline & Low TFL & 19 & $5(26.3 \%)$ & $14(73.6 \%)$ \\
\hline & Ungrouped cases & 55 & $42(76.4 \%)$ & $13(23.6 \%)$ \\
\hline & Total & 200 & & \\
\hline
\end{tabular}

\footnotetext{
a $92.5 \%$ of selected cases in the test sub-sample correctly classified

b $86.7 \%$ of selected cases in the replication sub-sample correctly classified.
} 


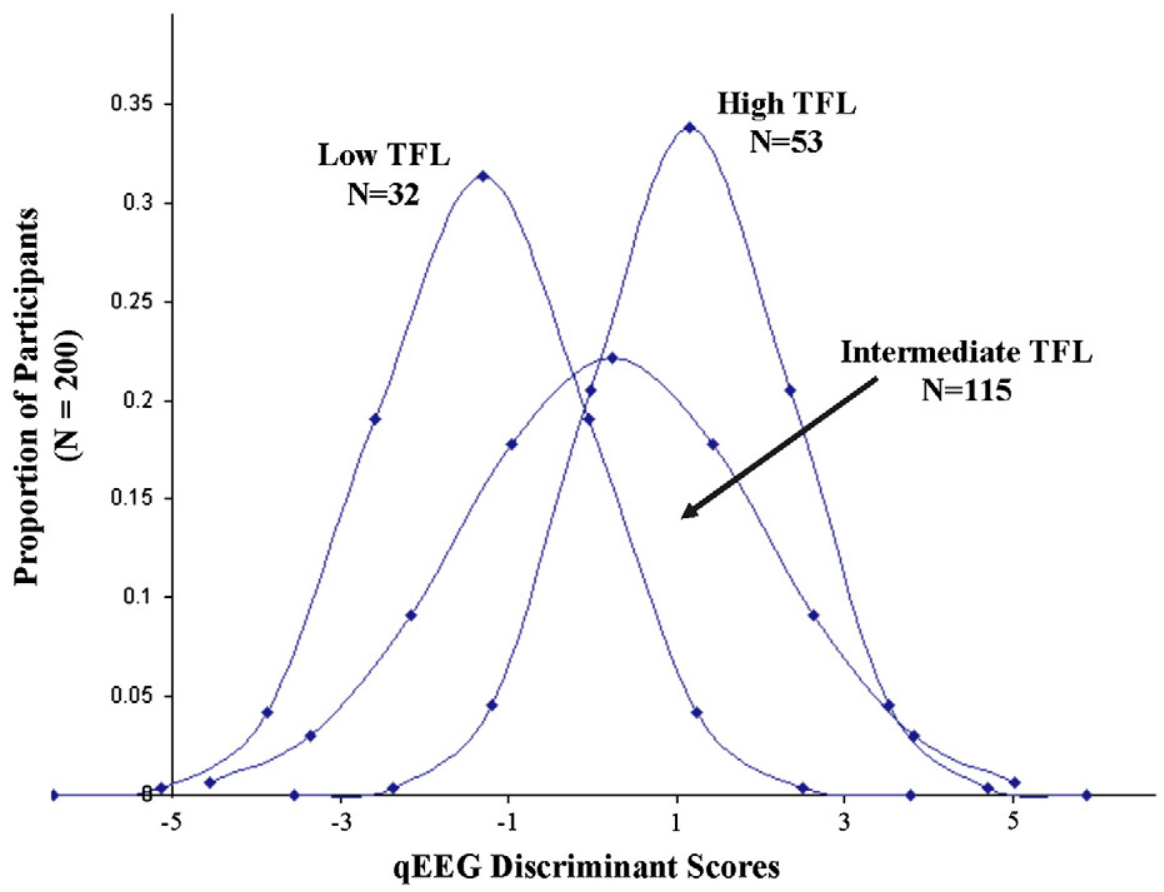

Fig. 2. Histogram of the discriminant functions using TFL scores.

\section{Discussion}

In support of Research question \#1, the findings of the current research suggest that transformational leadership can be identified through variables collected as part of an EEG power spectral analysis. That is, individuals who score high on transformational leadership can be delineated with a high degree of accuracy from those who score low based on qEEG variables. These findings would indicate that there may be a neural "signature" for transformational leadership. However, as stated earlier, transformational leader behavior is multifaceted in terms of its basis and manifestation. Accordingly, the development of

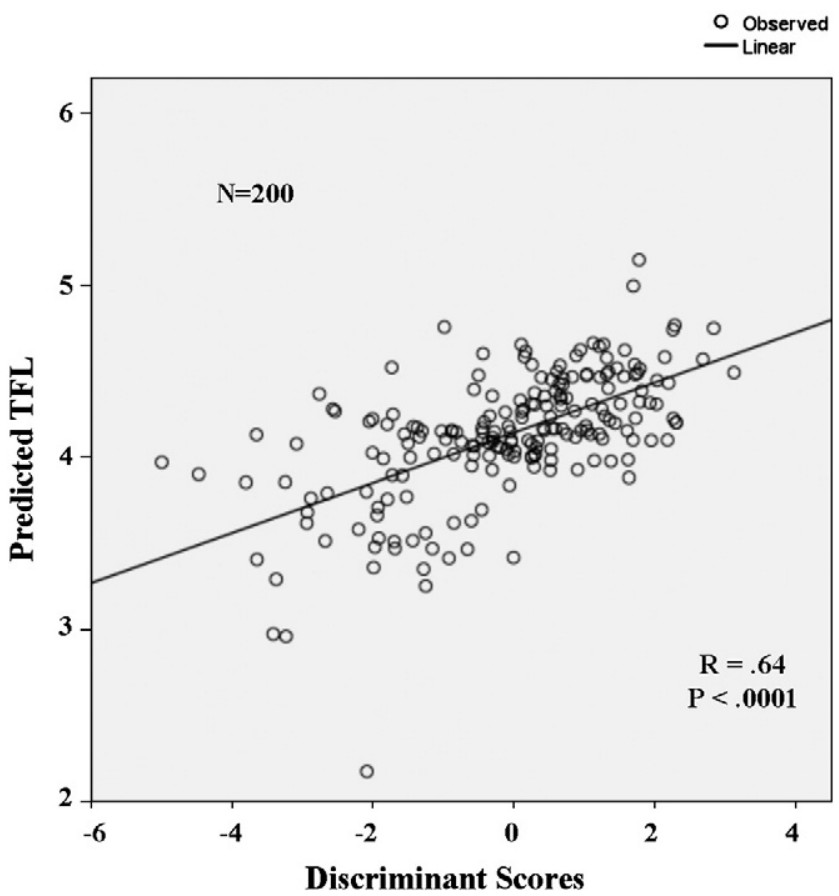

Fig. 3. Prediction of TFL scores for all participants $(\mathrm{N}=200)$ based on the multivariate regression analysis on the $\mathrm{y}$-axis and the discriminant scores on the $\mathrm{x}$-axis. 


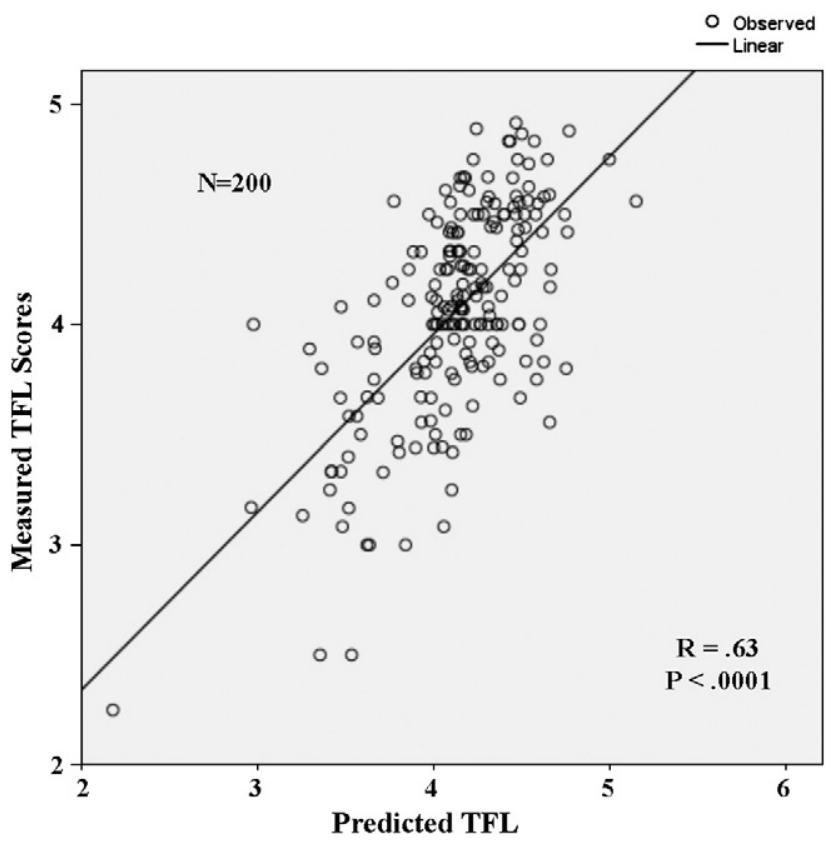

Fig. 4. Measured TFL scores for all participants $(\mathrm{N}=200)$ on the $\mathrm{y}$-axis and the multivariate regression prediction of TFL scores on the $\mathrm{x}$-axis.

neuroscientifically-based theory to understand its etiology may require the inductive approach used here that fuses knowledge and methods from the social and life sciences.

Many interesting anatomical features emanate from our qEEG analysis of the brains of leaders. Generally, patterns from our holistic approach seem consistent with patterns discussed in prior cognitive neuroscience research that targeted more focused areas. For instance, relevant to Research question \#2, it is noteworthy that qEEG variables involving pre-frontal and frontal lobes represent $40 \%$ of the selected group of variables in the discriminant analysis. This is followed by the temporal lobes (17.8\%), central and parietal areas (15.5\% each), and the occipital lobes (only $11.1 \%$ ).

In the context of transformational leadership, the frontal dominance is not at all surprising. In line with prior neuroscience work summarized earlier, these findings point toward areas of the brain that have been associated with "executive functions" (Miller \& Cohen, 2001), such as planning and foresight (Aziz-Zadeh et al., 2009; Bowden \& Jung-Beeman, 2003; Carrillo-de-la-Pena \& Garcia-Larrea, 2007; Kounios et al., 2008). The frontal areas have also been associated with the effective handling of emotionsboth in terms of managing one's own emotions, as well as dealing with the emotions (e.g., emotional uncertainties) of others (BarOn, Tranel, Denburg, \& Bechara, 2005; Naqvi et al., 2006). In addition, the right frontal region is largely responsible for adding meaning to verbal communication, like irony, sarcasm, emphasis, accentuation and intonation (George et al., 1996). There is also growing evidence that the frontal right region helps us to understand novel situations (Goldberg, 2009). Further, the frontal lobes depend on receptive and regulatory functions of other cortical regions such as the temporal lobes. For instance, numerous semantic memory activities that occur in the temporal lobe, and in the entorhinal and perirhinal cortex, act as important interfaces between the hippocampus and neocortex regions. Those regions receive highly-processed sensory information from all sensory regions and are involved in memory formation, memory consolidation, and memory optimization (Schacter, 1996). In total, the neural regions identified in our research are in line with previous studies, and their functions represent qualities reflective of transformational leaders.

\subsection{Patterns based on types of qEEG variables}

Beyond the frontal and temporal areas stressed in our theoretical basis, relevant to Research questions \#2 and 3, there are other anatomical or topographic patterns that emanate from our discriminant analysis that are further indicative of transformational leadership. Specifically, we consider patterns of significant correlations between transformational leadership and three types of qEEG variables: (1) amplitude asymmetry, (2) coherence, and (3) phase lock duration (refer to Table 2).

Consider that many of the amplitude asymmetry variables selected for the discriminant function involve the frontal right hemisphere, across all frequency ranges. Each right-front source is positively correlated with transformational leadership $(r=.25$, $\mathrm{p}<.05$, on average), while the only left-front location is negatively correlated $(r=-.23, p<.05$ on average). Interestingly, clinical research has shown the reverse pattern of correlations with regard to anxiety disorder or difficulties controlling one's mood (e.g., Ehlers, Wall, Garcia-Andrade, \& Phillips, 2001). Thus, our obtained pattern may suggest that transformational leaders have an affinity to keep anxiety levels to a minimum, and they tend to be able to control their emotions, even in difficult situations. Kislova and Rusalova (2009) would argue, for instance, that this is reflective of individuals who would successfully recognize emotions in 
the voice of colleagues and excel at nonverbal communication. Such capabilities are of great importance not only for interpersonal interaction, but also in the identification of a speaker's personality (Morozov, 1985), and for monitoring the emotional states of colleagues working in stressful conditions (Frolov \& Milovanova, 1996).

We found that coherence variables representing electrode combinations in the left-front cortex are negatively correlated with transformational leadership $(\mathrm{r}=-.22, \mathrm{p}<.05$, on average), whereas those in the right frontal, right temporal and right occipital lobe are positively correlated with transformational leadership $(r=.23, p<.05$, on average). Burst metrics, which logically complement coherence measures, are dominated by left hemisphere and medial regions that are all negatively correlated with transformational leadership $(\mathrm{r}=-.25, \mathrm{p}<.05$, on average). This pattern is indicative of a well-differentiated brain in those areas. In sum, our evidence shows that transformational leaders tend to have less connectivity (or more differentiation) in the left hemisphere, and more connectivity (or more integration) in the right hemisphere (frontal and central regions). Hellige (1990) offered some evidence that the left hemisphere is largely responsible for the rational or analytic consideration of details in one's reasoning and decision-making. When making decisions, the left hemisphere may to some degree engage in the rational weighing of alternatives. As noted earlier, decreased levels of coherence in the left hemisphere, such as those obtained here for transformational leaders, would indicate more differentiation or capacity for complex thinking with regard to issues and alternative courses of action (Thatcher et al., 1986, 2008). In turn, complexity of thinking may be relevant to such behaviors as effective vision formation and intellectual stimulation, both of which are pertinent to transformational leadership.

Lastly, all five of the phase lock duration electrode combinations were found to be negatively correlated with transformational leadership ( $\mathrm{r}=-.25, \mathrm{p}<.05$ on average). That is, transformational leaders tend to have shorter phase lock duration across a large portion of their brain. Phase lock duration represents periods of synchrony of selected clusters of neurons that temporarily mediate local and global functions in the brain (Buzaski, 2006; Thatcher et al., 2008, 2009; Thatcher, North, \& Biver, 2009). If the phase lock period is too long, then there is likely to be less cognitive flexibility, less neural resources available to be allocated, and reduced cognitive ability (Thatcher et al., 2008). In contrast, the correlations between transformational leadership and the five phase shift, electrode combinations offer an additional conclusion. That is, while four of the five correlations present a pattern that is similar to phase lock duration, the left pre-frontal region is positively correlated with transformational leadership ( $\mathrm{r}=.24$, $\mathrm{p}<.01$ ). Longer phase shift duration allows greater recruiting of neurons, and generally, more neural resources available to solve the tasks at hand - in a brain region responsible for executive functions, clearly associated with transformational leadership. Thus, transformational leaders tend to have more cognitive flexibility and additional neural resource available to tackle cognitive issues.

In sum, we see our work as potentially helping to provide insight for new research and theory pertaining to transformational leadership and its origins. Regarding the latter, in recent times, researchers have directed their attention to personal, behavioral qualities, such as personality (e.g., Bono \& Judge, 2004). However, in line with the work of Senior et al. (2011), the present findings would suggest that theory should also address the biological origins in general, and neurological basis in particular, of effective leadership behavior. In short, emerging neuroscience may reveal insights into effective forms of leadership.

\subsection{Methodological limitations}

A limitation of our research is the sample size of the current study. Although our sample included 200 individuals in leadership roles across various types of organizations, functional areas, and age groups, it was nevertheless relatively small in relation to the 58 variables used in our discriminant analysis. With that said, our cross-validation using the validation sub-sample lends strong support to the discriminant function obtained from the test sub-sample. Nevertheless, we acknowledge that additional data will need to be collected in order to define a more stable and precise function that incorporates the most discriminating variables. The relationships between the discriminant scores and the predicted TFL scores $(R=.64, p<.001)$, and between the predicted TFL scores and the measured TFL scores $(\mathrm{R}=.63, \mathrm{p}<.001)$, suggest that, with additional data, the choice of variables and calculated coefficients in the canonical discriminant function could become more definitive. Thus, additional data could provide accuracy beyond the high/low group level of our current analyses.

Vul, Harris, Winkielman, and Pashler (2009) provided an opportunity for the social neuroscience discipline to consider if existing studies suffered from severe statistical flaws. Vul et al. (2009) claimed that brain-behavior correlations in many neuroscience studies and those in related disciplines may be "spurious" (p. 274), "inflated to the point of being completely untrustworthy" (p. 284), and "should not be believed" (p. 285). At issue are the brain-imaging studies that do not adequately guard against the possibility that observed brain patterns are simply random. We leave the defense of the discipline to others (see Lieberman, Berkman, \& Wager, 2009; Poldrack \& Mumford, 2009). However, the issue of multiple comparisons is pertinent to our analysis, as it is with all neuroimaging studies that deal with thousands of brain voxels-and accordingly, will be discussed below.

In statistics, it is a property of any analysis in which multiple tests are conducted that observed effect sizes in significance tests will be inflated (Tukey, 1977). Errors in inference, including confidence intervals that fail to include their corresponding population parameters, or hypothesis tests that incorrectly reject the null hypothesis, are more likely to occur when one considers the set as a whole (Tukey, 1977). Several statistical techniques have been developed to prevent this from occurring, allowing significance levels for single and multiple comparisons to be directly compared. These techniques generally require a stronger level of evidence to be observed in order for an individual comparison to be deemed "significant", so as to compensate for the number of inferences being made. A commonly used approach, the Bonferroni correction, retains only the tests having a type I error rate $=\alpha / n$ so that the total error rate for the multiple comparisons does not exceed $\alpha$. In our study, the Bonferroni method would have required p-values to be smaller than .05/10,383 to declare significance. Indeed, since brain variables tend to be highly correlated, this threshold would impose an overly conservative and impractical limit for exploratory studies like our own. 
As such, we acknowledge the possibility of the inclusion of spurious neural variables in the set that was found to be correlated with TFL. Nevertheless, we argue that several other characteristics of our study mitigate this possibility and provide support for the relability and validity of our findings. First, if measurement error is a random phenomenon, false-positive relationships are also likely to be randomly and uniformly distributed throughout the brain. If our study only reported significant correlations in regions uniformly distributed over the brain, there would be reason to question whether they were meaningful as a set. However, we report patterns and clusters (for instance, $2 / 3$ of the variables emanate from the frontotemporal lobes) that are clearly not uniformily distributed. Further, the patterns and clusters appear in areas that have been shown a priori to be in regions that are consistent with brain networks underlying social and affective phenomena theoretically associated with TFL. Second, following Thatcher et al. (2005), the goal of our procedure was not to draw a brain-behavior inference per se, but to ease demands on sample size by only considering the most significant variables over less significant ones. Logically, those would be the same variables retained when applying a Bonferroni correction. Third, and most importantly, the inclusion of spurious variables in any discriminant analysis would only decrease the sensitivity and specificity of the derived function, especially when tested on a replication data set. In short, we have confidence in the process that was used to identify a discriminant function predictive of transformational leadership based on information derived from EEG imaging.

\subsection{Additional implications and conclusion}

The identification of leadership qualities based on neurological variables may be interesting from a basic research viewpoint. However, it is not immediately apparent as to the applicability of such knowledge. One possible benefit of the type of research pursued here is that we might start to see more ecologically-sound approaches to the assessment of leadership. It can be argued that neurologically-based assessments are void of the types of biases (e.g., information processing biases, leniency error, and so forth) that can plague psychometric approaches, such as surveys. Accordingly, neurological assessment might ultimately be used to help facilitate the selection and placement of leaders in organizations. In short, neurological assessment may provide a new "microscope" to look at the biological sources of leader behavior. But with that said, and in accordance with Senior et al. (2011), we caution that the identification of brain activity alone may not be sufficient to infer the requirement of such activity for the realization of particular behaviors, or patterns of behaviors such as transformational leadership.

Leadership itself is a complex process involving not only the behaviors of leaders, but also that of followers, as well as aspects of the context in which all of these elements exist (Yukl, 1999). Thus, to more fully understand effective leadership, the brain mapping of followers, as well as leaders, may ultimately be necessary. Relatedly, leadership is increasingly seen as a shared or distributed process among individuals, rather than being the exclusive domain of a particular individual, or even those in formal leadership positions (Day, Gronn, \& Salas, 2004; Pearce \& Conger, 2003). Thus, conceiving of effective leadership in this manner could imply the simultaneous brain mapping of entire management teams, as well as individuals who may not be in formal leadership roles, which is an emerging area of neuroscience that examines neurophysiological synchronies (e.g., Stevens, Galloway, Berka, \& Sprang, 2009).

In conclusion, the current study has demonstrated that transformational leaders can be distinguished from nontransformational leaders on the basis of a validated discriminant function derived from qEEG data. Research of this nature can provide insights as to the neurological origins of such forms of leadership. We encourage additional research that furthers the connection between neuroscience and leadership.

\section{Acknowledgements}

The authors gratefully acknowledge the financial support of the Defense Advanced Research Projects Agency (DARPA award number N10P20006) and the United States Military Academy at West Point (USMA award number W911SD-08-P-0671). We are also grateful to Carl Senior, Nick Lee, Michael Butler and three anonymous reviewers for their insightful suggestions and constructive criticism.

\section{References}

Anokhin, A. P., Lutzenberger, W., \& Birbaumer, N. (1999). Spatiotemporal organization of brain dynamics and intelligence: An EEG study in adolescents. International Journal of Psychophysiology, 33, 259-273.

Arvey, R. D., Rotundo, M., Johnson, W., Zhang, Z., \& McGue, M. (2006). The determinants of leadership role occupancy: Genetic and personality factors. The Leadership Quarterly, 17, 1-20.

Arvey, R. D., Zhang, Z., Avolio, B. J., \& Krueger, R. F. (2007). Development and genetic determinants of leadership role occupancy among females. Journal of Applied Psychology, 92, 693-707.

Awh, R. Y., \& Waters, D. (1974). A discriminant analysis of economic, demographic, and attitudinal characteristics of bank charge-card holders: A case study. The Journal of Finance, 29, 973-980.

Aziz-Zadeh, L., Kaplan, J. T., \& Iacoboni, M. (2009). “Aha!”: The neural correlates of verbal insight solutions. Human Brain Mapping, 30, $908-916$.

Babiloni, C., Frisoni, G. B., Vecchio, F., Pievani, M., Geroldi, C., De Carli, C., Ferri, R., Vernieri, F., Lizio, R., \& Rossini, P. M. (2010). Global functional coupling of resting EEG rhythms is related to white-matter lesions along the cholinergic tracts in subjects with amnesic mild cognitive impairment. Journal of Alzheimers Disease, $19,859-871$.

Bar-On, R., Tranel, D., Denburg, N. L., \& Bechara, A. (2005). Exploring the neurological substrate of emotional and social intelligence. In J. T. Cacioppo, \& G. G. Bernston (Eds.), Key readings in social psychology: Social neuroscience (pp. 223-237). New York: Psychology Press.

Bass, B. M., \& Avolio, B. J. (1990). Transformational leadership development: Manual for the Multifactor Leadership Questionnaire. Menlo Park, CA: Mind Garden.

Bass, B. M., \& Avolio, B. J. (1994). Shatter the glass ceiling: Women may make better managers. Human Resource Management, 33, 549-560.

Bass, B. M., \& Bass, R. (2009). Bass handbook of leadership: Theory, research, and managerial applications (4th ed). New York: Free Press. 
Bono, J. E., \& Judge, T. A. (2004). Personality and transformational and transactional leadership: A meta analysis. Journal of Applied Psychology, 89, 901-910.

Bosl, et al. (2011). EEG complexity as a biomarker for autism spectrum disorder risk. BMC Medicine, 9-18.

Bowden, E. M., \& Jung-Beeman, M. (2003). Aha! Insight experience correlates with solution activation in the right hemisphere. Psychonomic Bulletin \& Review, 10, $730-737$.

Braitenberg, V. (1978). Cortical architectonics: General and areal. In M. A. B. Brazier, \& H. Petsche (Eds.), Architectonics of the cerebral cortex (pp. 443-465). New York: Raven Press.

Butler, M. J. R., \& Senior, C. (2007). Toward an organizational cognitive neuroscience. Annals of the New York Academy of Sciences, 1118, 1-17.

Buzaski, G. B. (2006). Rhythms of the brain. New York: Oxford University Press.

Cacioppo, J. T., Berntson, G. G., \& Nusbaum, H. C. (2008). Neuroimaging as a new tool in the toolbox of psychological science. Current Directions in Psychological Science, $17,62-67$.

Cacioppo, J. T., et al. (2003). Just because you're imaging the brain doesn't mean you can stop using your head: A primer and set of first principles. Journal of Personality and Social Psychology, 85, 650-661.

Carrillo-de-la-Pena, M. T., \& Garcia-Larrea, L. (2007). Right frontal event related EEG coherence (ERCoh) differentiates good from bad performers of the Wisconsin Card Sorting Test (WCST). Neurophysiologie Clinique, 37, 63-75.

Case, R. (1992). The mind's staircase: Exploring the conceptual underpinnings of children's thought and knowledge. Hillsdale, NJ: Erlbaum.

Cohen, R. A., Kaplan, R. F., Moser, D. J., Zuffante, P., \& Jenkins, M. A. (1999). Attention and executive functioning associated with bilateral anterior cingulotomy: Alteration of intention and self-initiated action. Journal of Neuropsychiatry and Clinical Neuroscience, 11, 444-453.

Cooper, R., Winter, A. L., Crow, H. J., \& Walter, W. G. (1965). Comparison of subcortical, cortical and scalp activity using chronically indwelling electrodes in man. Electroencpehalography and Clinical Neurophysiology, 18, 217-222.

Craig, A. D. (2009). How do you feel-now? The anterior insula and human awareness. National Review of Neuroscience, 10, 59-70.

Damasio, A. R. (1989). Time-locked multiregional retroactivation: A systems-level proposal for the neural substrates of recall and recognition. Cognition, 33, 25-62.

Day, D. V., Gronn, P., \& Salas, E. (2004). Leadership capacity in teams. The Leadership Quarterly, 15, 857-880.

De Vico Fallani, F., et al. (2010). Cortical network analysis in patients affected by schizophrenia brain topography. Brain Topography, 23, 214-220.

DeCotiis, T. A., \& LeLouarn, J. (1981). A predictive study of voting behavior in a representation election using union instrumentality and work perceptions. Organizational Behavior and Human Performance, 27, 103-118.

Ehlers, C. L., Wall, T. L., Garcia-Andrade, C., \& Phillips, E. (2001). EEG asymmetry: Relationship to mood and anxiety. Biological Psychiatry, 50, 129-136.

Fridell, M., Newcom-Belcher, R., \& Messner, P. E. (2009). Discriminate analysis gender public school principal servant leadership differences. Leadership E Organization Development Journal, 30, 722-736.

Frolov, M. V., \& Milovanova, G. B. (1996). Electrophysiological interference and monitoring of the state of human operators. Moscow: Nauka.

Fuster, J. M. (1999). Memory in the cerebral cortex: An empirical approach to neural networks in the human and nonhuman primate. Cambridge, MA: MIT Press.

Gasser, T., Jennen-Steinmetz, C., \& Verleger, R. (1987). EEG coherence at rest and during a visual task in two groups of children. Electroencephalography and Clinical Neurophysiology, 67, 151-158.

George, J. M. (1990). Personality, affect, and behavior in groups. Journal of Applied Psychology, 75, 107-116.

George, M. S., et al. (1996). Understanding emotional prosody activates right hemisphere regions. Archives of Neurology, 53, 665-670.

Goldberg, E. (2009). The new executive brain: Frontal lobes in a complex world. New York: Oxford University Press.

Hanlon, H. W., Thatcher, R. W., \& Cline, M. J. (1999). Gender differences in the development of EEG coherence in normal children. Developmental Neuropsychology, $16,479-506$

Hannah, S. T., Woolfolk, L., \& Lord, R. G. (2009). Leader self-structure: A framework for positive leadership. Journal of Organizational Behavior, 30, 269-290.

Hellige, J. B. (1990). Hemispheric asymmetry. Annual Review of Psychology, 41, 55-80.

Hines, T. (1987). Left brain/right brain mythology and implications for management and training. Academy of Management Review, 12, 600-606.

Huberty, C. J. (1994). Applied discriminant analysis. New York: Wiley and Sons.

IBM (2011). SPSS statistical software, Version 19.0. Chicago: SPSS Inc.

James, L. R., Demaree, R. G., \& Wolf, G. (1984). Estimating within-group inter-rater reliability with and without response bias. Journal of Applied Psychology, 69, $85-98$.

James, L. R., Demaree, R. G., \& Wolf, G. (1993). R(wg)-an assessment of within-group inter-rater agreement. Journal of Applied Psychology, 78, 306-309.

Jausovec, N., \& Jausovec, K. (2001). Differences in EEG current density related to intelligence. Brain Research. Cognitive Brain Research, 12, 55-60.

Jausovec, N., \& Jausovec, K. (2003). Spatiotemporal brain activity related to intelligence: A low resolution brain electromagnetic tomography study. Brain Research. Cognitive Brain Research, 16, 267-272.

John, E. R. (2002). The neurophysics of consciousness. Brain Research Review, 39, 1-28.

John, E. R. (2005). From synchronous neural discharges to subjective awareness. Progress in Brain Research, 150, 143-171.

Jones, N. A., Field, T., \& Davalos, M. (2000). Right frontal EEG asymmetry and lack of empathy in preschool children of depressed mothers. Child Psychiatry and Human Development, 30, 189-204.

Judge, T. A., \& Bono, J. E. (2000). Five-factor model of personality and transformational leadership. Journal of Applied Psychology, 85, 751-765.

Judge, T. A., \& Piccolo, R. F. (2004). Transformational and transactional leadership: A meta-analytic test of their relative validity. Journal of Applied Psychology, 89, 755-768.

Kahana, M. J. (2006). The cognitive correlates of human brain oscillations. Journal of Neuroscience, 26, 1669-1672.

Kislova, O. O., \& Rusalova, M. N. (2009). EEG coherence in humans: Relationship with success in recognizing emotions in the voice. Neuroscience and Behavioral Physiology, 39, 545-552.

Kjaer, T., Nowak, M., \& Lou, H. (2002). Reflective self-awareness and conscious states: PET evidence for a common midline parietofrontal core. Neurolmage, 17, 1080.

Koles, Z. J., Lind, J. C., \& Flor-Henry, P. (2010). Gender differences in brain functional organization during verbal and spatial cognitive challenges. Brain Topography, 23. 199-204.

Kounios, J., et al. (2008). The origins of insight in resting-state brain activity. Neuropsychologia, 46, 281-291.

Kozlowski, S. W. J., \& Hattrup, K. (1992). A disagreement about within-group agreement: Disentangling issues of consistency versus consensus. Journal of Applied Psychology, 77, 161-167.

Lee, N., \& Chamberlain, L. (2007). Neuroimaging and psychophysiological measurement in organizational research. Annals of the New York Academy of Sciences, $1118,18-42$

Lewis, D. A. (1997). Development of the primate frontal cortex. In M. S. Kershaw, \& R. M. Murray (Eds.), Neurodevelopment and adult psychopathology (pp. 12-30). Cambridge, UK: Cambridge University Press.

Lieberman, M. D. (2007). Social cognitive neuroscience: A review of core processes. Annual Review of Psychology, 58, 259-289.

Lieberman, M. D., Berkman, E. T., \& Wager, T. D. (2009). Correlations in social neuroscience aren't voodoo: Commentary on Vul et al. (2009). Perspectives on Psychological Science, 4, 299-307.

Lopes Da Silva, F. H. (1995). Dynamic of electrical activity of the brain, networks, and modulating systems. In P. Nunez (Ed.), Neocortical dynamics and human EEG rhythms (pp. 249-271). (1st edition). New York: Oxford University Press.

Lord, R. G., \& Maher, K. J. (1991). Leadership and information processing: Linking perceptions, attributions and performance. Boston, MA: Unwin Hyman.

Lowe, K. B., Kroeck, K. G., \& Sivasubramaniam, N. (1996). Effectiveness correlates of transformational and transactional leadership: A meta-analytic review of the MLQ literature. The Leadership Quarterly, 7, 385-425.

Marosi, E., et al. (1999). Broad band spectral parameters correlated with different I.Q. measurements. International Journal of Neuroscience, 97, 17-27.

Martin-Loeches, M., Munoz-Ruata, J., Martinez-Lebrusant, L., \& Gomez-Jari, G. (2001). Electrophysiology and intelligence: the electrophysiology of intellectual functions in intellectual disability. Journal of Intellectual Disability Research, 45, 63-75. 
Miller, E. K., \& Cohen, J. D. (2001). An integrative theory of prefrontal cortex function. Annual Review of Neuroscience, 24, 167-202.

Morozov, V. P. (1985). Emotional hearing in humans. Zhurnal Evoliutsionnoi Biokhimii I Fiziologii, 21, 568-577.

Naqvi, N., Shiv, B., \& Bechara, A. (2006). The role of emotion in decision making: A cognitive neuroscience perspective. Current Directions in Psychological Science, 15 , 260-264.

Niedermeyer, E., \& Silva, F. L. (1995). Electroencephalography: Basic principles, clinical applications and related fields. Baltimore: Williams \& Wilkin.

Nolte, J. (2002). The human brain: An introduction to its functional anatomy. St. Louis, MO: Mosby.

Norusis, M. J. (1994). SPSS advanced statistics 6.1. Chicago, IL: SPSS, Inc.

Nunez, P. (1981). Electrical fields of the brain. New York: Oxford University Press.

Nunez, P. (1995). Neocortical dynamics and human EEG rhythms. New York: Oxford University Press.

Ochsner, K. N., \& Lieberman, M. D. (2001). The emergence of social cognitive neuroscience. American Psychologist, 56, 717-734.

Pearce, C. L., \& Conger, J. A. (2003). All those years ago: The historical underpinnings of shared leadership. In C. L. Pearce, \& J. A. Conger (Eds.), Shared leadership: Reframing the hows and whys of leadership (pp. 1-18). Thousand Oaks, CA: Sage.

Perreault, W. D., Jr., French, W. A., \& Harris, C. E., Jr. (1977). Use of multiple discriminant analysis to improve the salesman selection process. Journal of Business, 50, $50-62$.

Pikovsky, A., Rosenblum, M. G., \& Kurth, J. (2003). Synchronization: Universal concept in nonlinear science. Cambridge, MA: Cambridge University Press.

Poldrack, R. A., \& Mumford, J. A. (2009). Independence in ROI analysis: Where is the voodoo? Social Cognitive and Affective Neuroscience, 4, $208-213$.

Raichle, M. E., \& Gusnard, D. A. (2002). Appraising the brain's energy budget. Proceedings of the National Academy of Science USA, 99, 10237-10239.

Raichle, M. E., \& Snyder, A. Z. (2007). A default mode of brain function: A brief history of an evolving idea. Neurolmage, 37, 1083-1090.

Rizzuto, D. S., et al. (2003). Reset of human neocortical oscillations during a working memory task. Proceedings of the National Academy of Science USA, 100, 7931-7936.

Salloway, S. P., Malloy, P. F., \& Duffy, J. D. (2001). The frontal lobes and neuropsychiatric illnesses. Washington, DC: American Psychiatric Publishing.

Schacter, D. L. (1996). Searching for memory: The brain, the mind, and the past. New York: BasicBooks.

Scherg, M. (1990). Fundamentals of dipole source potential analysis. Advances in Audiology, 6, 40-69.

Schmid, R. G., Tirsch, W. S., \& Scherb, H. (2002). Correlation between spectral EEG parameters and intelligence test variables in school-age children. Clinical Neurophysiology, 113, 1647-1656.

Schore, A. N. (1994). Affect regulation and the origin of the self: The neurobiology of emotional development. Hillsdale NJ: Erlbaum.

Schultz, A., \& Braitenberg, V. (2002). The human cortical white matter: Quantitative aspects of corticocortical long-range connectivity. In A. Schultz, \& R. Miller (Eds.), Cortical areas: Unity and diversity (pp. 377-386). London: Conceptual Advances in Brain Research.

Senior, C., Lee, N., \& Butler, M. (2011). Organizational cognitive neuroscience. Organization Science, 22, 804-815.

Shamir, B., Zakay, E., Breinin, E., \& Popper, M. (1998). Correlates of charismatic leader behavior in military units: Subordinates' attitudes, unit characteristics, and superiors' appraisals of leader performance. Academy of Management Journal, 41, 387-409.

Shulman, G. L., et al. (1997). Common blood flow changes across visual tasks: II. Decreases in cerebral cortex. Journal of Cognitive Neuroscience, 9, 648-663.

Sowell, E. R., et al. (2010). Differentiating prenatal exposure to methamphetamine and alcohol versus alcohol and not methamphetamine using tensor-based brain morphometry and discriminant analysis. Journal of Neuroscience, 30, 3876-3885.

Steriade, M. (1995). Cellular substrates of brain rhythms. In E. Niedermeyer, \& Lopes da Silva (Eds.), Electroencephalography (pp. 31-83). Baltimore: Williams and Wilkins.

Stevens, R., Galloway, T., Berka, C., \& Sprang, M. (2009). Can neurophysiologic synchronies provide a platform for adapting team performance? In D. D. Schmorrow, I. V. Estabrooke, \& M. Grootjen (Eds.), Foundations of augmented cognition. Neuroergonomics and operational neuroscience (pp. 658-667). Berlin: SpringerVerlag.

Tesche, C. D., \& Karhu, J. (2000). Theta oscillations index human hippocampal activation during a working memory task. Proceedings of the National Academy of Science USA, 97, 919-924.

Thatcher, R. W., Biver, C., \& North, D. (2003). Quantitative EEG and the Frye and Daubert standards of admissibility. Clinical Electroencephalography, 34, $39-53$.

Thatcher, R. W., \& John, E. R. (1977). Functional neuroscience: Foundations of cognitive processing. Mahway, NJ: Lawrence Erlbaum.

Thatcher, R. W., Krause, P., \& Hrybyk, M. (1986). Corticocortical association fibers and EEG coherence: A two compartmental model. Electroencephalography and Clinical Neurophysiology, 64, 123-143.

Thatcher, R. W., McAlaster, R., Lester, M. L., Horst, R. L., \& Cantor, D. S. (1983). Hemispheric EEG asymmetries related to cognitive functioning in children. In A. Perecuman (Ed.), Cognitive processing in the right hemisphere (pp. 125-144). New York: Academic Press.

Thatcher, R. W., North, D., \& Biver, C. (2005). EEG and intelligence: Univariate and multivariate comparisons between EEG coherence, EEG phase delay and power. Clinical Neurophysiology, 116, 2129-2141.

Thatcher, R. W., North, D., \& Biver, C. (2008). Development of cortical connectivity as measured by EEG coherence and phase. Human Brain Mapping, 29, $1400-1415$.

Thatcher, R. W., North, D., \& Biver, C. (2009). Self organized criticality and the development of EEG phase reset. Human Brain Mapping, 30, 553-574.

Thatcher, R. W., North, D., Curtin, R., Walker, R. A., Biver, C., Gomez, M. J. F., \& Salazar, A. (2001). An EEG severity index of traumatic brain injury. Journal of Neuropsychiatry and Clinical Neuroscience, 13, 77-87.

Thatcher, R. W., Walker, R. A., Biver, C., North, D., \& Curtin, R. (2003). Quantitative EEG normative databases: Validation and clinical correlation. Journal of Neurotherapy, 7, 87-122 (No. $3 / 4$ ).

Thatcher, R. W., Walker, R. A., Gerson, I., \& Geisler, F. H. (1989). EEG discriminant analyses of mild head trauma. Electroencephalography and Clinical Neurophysiology, 73, 94-106.

Tononi, G., Sporns, O., \& Edelman, G. M. (1994). A complexity measure for selective matching of signals by the brain. Proceedings of the National Academy of Science USA, 93, 3422-3427.

Tukey, J. W. (1977). Exploratory data analysis. Reading, MA: Addison-Wesley.

van Baal, G. C., Boomsma, D. I., \& de Geus, E. J. (2001). Longitudinal genetic analysis of EEG coherence in young twins. Behavioral Genetics, 31, 637-651.

Van Beijsterveldt, C. E., Molenaar, P. C., de Geus, E. J., \& Boomsma, D. I. (1998). Genetic and environmental influences on EEG coherence. Behavioral Genetics, 28, 443-453.

Vul, E., Harris, C., Winkielman, P., \& Pashler, H. (2009). Puzzlingly high correlations in fMRI studies of emotion, personality, and social cognition. Perspectives on Psychological Science, 4, 274-290.

Waldman, D. A., Balthazard, P. A., \& Peterson, S. (2011). The neuroscience of leadership: Can we revolutionize the way that leaders are identified and developed? Academy of Management Perspectives, 25(1), 60-74.

Yukl, G. (1999). An evaluation of conceptual weaknesses in transformational and charismatic leadership theories. The Leadership Quarterly, 10, 285-305.

Zaccaro, S. J., Foti, R. J., \& Kenny, D. A. (1991). Self-monitoring and trait-based variance in leadership: An investigation of leader flexibility across multiple group situations. Journal of Applied Psychology, 76, 308-315.

Zhang, Z., Ilies, R., \& Arvey, R. D. (2009). Beyond genetic explanations for leadership: The moderating role of the social environment. Organizational Behavior and Human Decision Processes, 110, 118-128. 